\title{
O PORTFÓLIO NO CURSO DE PEDAGOGIA: AMPLIANDO O DIÁLOGO ENTRE PROFESSOR E ALUNO
}

\author{
Benigna Maria de Freitas Villas Boas*
}

\begin{abstract}
O processo do portfólio gera inquietação e até desconforto, tamanho é o sentimento de reflexão acerca de tudo que nos é ensinado. Nós, alunos do PIE, não aceitamos mais o conhecimento como algo pronto e acabado, que deve ser transmitido e, sim, o conhecimento como algo a ser construído continuamente, renovando-se sempre.
\end{abstract}

(Professor-aluno do PIE)

RESUMO: Apresentam-se resultados de uma pesquisa realizada no Curso de Pedagogia para professores em exercício no início de escolarização (PIE), oferecido pela Faculdade de Educação da Universidade de Brasília. Nesse curso se adota o portfólio como procedimento de avaliação. Discutem-se: a) as percepçôes dos mediadores sobre as reaçôes dos professores-alunos quanto ao uso do portfólio; b) as percepçóes dos professores-alunos sobre a construção do seu portfólio. Constatou-se que: o portfólio era um procedimento de avaliação anteriormente desconhecido por todo o grupo; inicialmente, houve resistência por parte de alguns professoresalunos quanto à sua construção, mas, à medida que o processo foi se desenvolvendo, tanto os mediadores como os professores-alunos foram adquirindo segurança quanto ao uso desse procedimento avaliativo. O portfólio passou a ser o eixo organizador do trabalho pedagógico do curso. Conclui-se que, para que o portfólio faça parte da avaliação comprometida com a aprendizagem do professor-aluno e se apóie na construção, reflexão, criatividade, parceria,

* Doutora em educação pela Universidade Estadual de Campinas (UniCAMP) e professora da Faculdade de Educação da Universidade de Brasília (UNB). E-mail: mbboas@terra.com.br

Educ. Soc., Campinas, vol. 26, n. 90, p. 291-306, Jan./Abr. 2005

Disponível em <http://www.cedes.unicamp.br> 
O portfólio no curso de pedagogia: ampliando o diálogo...

auto-avaliação e autonomia, deve inserir-se no trabalho pedagógico que considere esses mesmos princípios.

Palavras-chave: Avaliação. Portfólio. Formação de professores.

PORTFOlio ASSESSMENT IN TEACHER EDUCATION: STRENGHTENING DIALOGUE BETWEEN TEACHER AND STUDENT

ABSTRACT: The article presents the results of a research conducted in the Pedagogy Course offered by the College of Education of the University of Brasília to in-service teachers who work in public elementary schools with grades one through four. The student-teachers are assessed by means of portfolios for evaluation procedure. The issues discussed are: a) the mediators' perceptions on student-teachers' reactions to the use of portfolios; b) the student-teacher's perceptions on the portfolio construction. It was noticed that: the use of the portfolio as an assessment procedure was previously unknown to the whole group; initially, there was resistance of some studentteachers regarding the portfolio construction, but as the process developed, the confidence not only of the mediators but also of the student-teachers increased; the portfolio became the organizer axle of the pedagogic course activities. In conclusion, for the portfolio to be part of the committed assessment process of student- teachers' learning and to be supported in construction, reflection, creativity, partnership, self-assessment and autonomy, it must be included in the pedagogical work that considers these same principles.

Key words: Assessment. Portfolio. Teacher education.

\section{Situando o tema}

$\mathbb{E}$

ste texto apresenta resultados da pesquisa conduzida no Curso de Pedagogia para professores em exercício no início de escolarização (PIE), oferecido pela Faculdade de Educação da Universidade de Brasília (UNB) em convênio com a Secretaria de Estado da Educação, do Distrito Federal. Esse curso atendeu, durante o ano de 2003, a 2.000 professores que têm apenas o Curso de Magistério em nível médio.

Principalmente o fato de os alunos do PIE serem professores em exercício provocou a necessidade da adoção de procedimento avaliativo que levasse em conta essa característica, de modo que eles não apenas "estudassem sobre a avaliação", como costumeiramente se faz, mas pra- 
ticassem a avaliação que buscasse superar a sua função tradicional de dar nota e aprovar e reprovar o aluno, mantendo, assim, a classificação, a seleção e a exclusão. Decidiu-se, então, pela utilização do portfólio, de modo que o curso trabalhasse simultaneamente a teoria e a prática da avaliação.

Como a avaliação por meio do portfólio constitui uma prática recente entre nós, o trabalho está sendo acompanhado e investigado pelo grupo de pesquisa "Avaliação e Organização do Trabalho Pedagógico" (cadastrado no CNPq e certificado pela UNB), que desenvolve, no momento, um grande projeto de pesquisa sobre "Práticas avaliativas inovadoras", no qual se insere a pesquisa cujos resultados são aqui descritos.

\section{O portfólio e a formação de professores}

O portfólio tem sido considerado no PIE um dos saberes a serem incorporados pelos professores-alunos e pelos mediadores (são os professores que se encontram regularmente com os professores-alunos), em articulação com a teoria e a prática. Ele é considerado não apenas um procedimento de avaliação, mas o eixo organizador do trabalho pedagógico, em virtude da importância que passa a ter durante todo o processo.

A avaliação tem sido um saber marginalizado na formação de professores. O uso do portfólio pode ser uma forma de colocá-la em debate justamente em um dos espaços a ela destinados, o da formação de professores. Isso requer mudança de concepção da avaliação: o professor deixa de ser o "examinador" e o aluno, o "examinado". Atua-se em parceria, sem com isso se perder o rigor e a seriedade que a atividade impõe. Pelo contrário, a avaliação torna-se mais exigente porque passa a ser, também, transparente. Isso não significa retirar a responsabilidade do professor para transferi-la ao professor-aluno, mas possibilitar a este vivenciar o processo que ele possa desenvolver com seus alunos, de modo que sejam superados os problemas que tanto temos combatido. Contudo, alerta Murphy (1997, p. 87), isso somente poderá ocorrer em ambiente que propicie o desenvolvimento profissional do professor, incluída a sua autonomia intelectual e condições adequadas de trabalho. 
O portfólio no curso de pedagogia: ampliando o diálogo...

Tardif (2002, p. 23) expressa sua vontade de "encontrar, nos cursos de formação de professores, uma nova articulação e um novo equilíbrio entre os conhecimentos produzidos pelas universidades 'a respeito' do ensino e os saberes desenvolvidos pelos professores 'em' suas práticas cotidianas". Até agora, afirma o autor, a formação para o magistério tem sido desenvolvida por meio de conhecimentos disciplinares geralmente produzidos em uma "redoma de vidro", e, posteriormente, aplicados na prática em forma de estágios e outras atividades semelhantes. $\mathrm{O}$ autor considera que os professores são atores competentes, sujeitos ativos e que sua prática não é apenas "um espaço de aplicação de saberes provenientes da teoria, mas também um espaço de produção de saberes específicos oriundos dessa mesma prática" (idem, ibid., p. 234). Isso significa que ele desenvolve e produz teoria da sua própria ação. Contudo, tal concepção da relação teoria e prática ainda é pouco vivenciada nos cursos de formação de professores. No caso do PIE, em que o aluno já é professor, o uso do portfólio possibilita o desenvolvimento da construção teórica e prática da avaliação: o trabalho do professor-aluno durante o curso é avaliado por meio de um procedimento que ele poderá desenvolver com seus próprios alunos, com o intuito de superação da avaliação classificatória e excludente. Parte das produções do seu portfólio constitui-se de reflexões sobre as possibilidades do seu uso com seus alunos.

A opção pelo uso do portfólio no PIE baseou-se, também, na crença de que o professor constrói a sua autonomia enquanto se forma. Nada melhor que a avaliação para contribuir com esse processo. Podese afirmar, com a ajuda de Contreras (2002, p. 204), que a "autonomia deve ser entendida como a independência intelectual que se justifica pela idéia da emancipação pessoal da autoridade e do controle repressivo, da superação das dependências ideológicas ao questionar criticamente nossa concepção de ensino na sociedade". Essa posição possibilita aos professores exercitarem o distanciamento crítico necessário ao trabalho pedagógico, que tem por objetivo a formação do cidadão para ter inserção social crítica.

O portfólio possibilita avaliar as capacidades de pensamento crítico, de articular e solucionar problemas complexos, de trabalhar colaborativamente, de conduzir pesquisa, de desenvolver projetos e de o aluno formular os seus próprios objetivos para a aprendizagem (Murphy, 1997, p. 72). O professor e o próprio aluno avaliam todas as atividades executadas durante um largo período de trabalho, levan- 
do em conta toda a trajetória percorrida. Não é uma avaliação classificatória nem punitiva. Analisa-se o progresso do aluno. Valorizam-se todas as suas produçôes: analisam-se as últimas comparando-as com as primeiras, de modo que se perceba o avanço obtido. Isso requer que a construção do portfólio se baseie em propósitos de cuja formulação o aluno participe, para que se desenvolva o sentido de "pertencimento". Murphy (1997, p. 73) considera que os portfólios "oferecem uma das poucas oportunidades escolares em que os alunos podem exercer seu julgamento, iniciativa e autoridade". Em cursos de formação de professores isso se torna fundamental porque a tendência é eles trabalharem com seus alunos da forma como foram tratados por seus professores.

No PIE o trabalho com o portfólio tem se apoiado em seis princípios básicos (Villas Boas, 2001, p. 207): a construção pelo próprio aluno, possibilitando-lhe fazer escolhas e tomar decisões; a reflexão sobre as suas produçôes; a criatividade, porque o aluno escolhe a maneira de organizar o portfólio e busca formas diferentes de aprender; a auto-avaliação pelo aluno, porque ele está permanentemente avaliando o seu progresso; a parceria professor-aluno e entre alunos, eliminando-se ações e atitudes verticalizadas e centralizadoras; a autonomia do aluno perante o trabalho.

\section{A pesquisa sobre o trabalho com o portfólio no PIE}

O objetivo da investigação foi analisar as percepções dos mediadores e dos professores-alunos sobre o uso do portfólio como procedimento de avaliação no PIE.

A primeira parte da pesquisa foi realizada por meio da aplicação de um questionário a 36 dos 55 mediadores, em setembro de 2002, para que respondessem às seguintes questóes: Como eles se sentiam ao participar de uma avaliação por meio de portfólio? Quais eram suas percepções sobre as reações dos professores-alunos quanto ao uso do portfólio?

Os dados coletados foram agrupados em sete itens de análise - a) os mediadores apresentam as reações dos professores-alunos ao uso do portfólio: "relação de amor e ódio"; b) portfólio: "o mais enriquecedor procedimento de avaliação"; c) "a gente faz o portfólio pensando em quem vai avaliar"; d) contribuições do portfólio para a formação dos pro- 
O portfólio no curso de pedagogia: ampliando o diálogo...

fessores-alunos: "transformação das nossas crenças, nossos valores e nossa atuação profissional"; e) entre dificuldades e facilidades: "uma dificuldade imensa de não comparar as pessoas e suas produções"; f) o mediador como coordenador do processo de construção do portfólio: "guerra de concepções"; g) necessidades/sugestôes.

Quanto ao primeiro item, que trata da relação de amor e ódio com o portfólio, as palavras/expressóes mais usadas pelos mediadores para descreverem as reaçóes dos professores-alunos são relacionadas à resistência e a dificuldades encontradas: medo, repulsa, dúvidas, insegurança, estresse, sofrimento, questionamento, angústia, preocupação, ansiedade, estranhamento, incompreensão, fardo a mais, rejeição, apreensão, aversão. As palavras mais freqüentes foram "medo" e "insegurança". O portfólio chegou a ser rotulado de o "bicho-papão" do curso.

Vários depoimentos esclarecem que, passado o primeiro momento de "estranhamento", vinha o segundo, traduzido pela sensação de "descoberta de algo novo" e de prazer, mas que, mesmo assim, havia um grupo que mantinha a sua discordância quanto ao uso do portfólio e, conseqüentemente, sua resistência. Segundo os depoimentos dos mediadores, parecia que, naquele momento, a maioria dos professores-alunos aprovava o uso do portfólio.

Além das reações negativas, que predominaram no início das atividades, "após orientações e textos de apoio, os professores-alunos começam a vislumbrar o caminho a trilhar" e a apresentar as seguintes atitudes positivas quanto ao novo procedimento avaliativo: curiosidade, admiração, alegria, paixão, orgulho pelo que têm conseguido produzir, aceitação, tranquiilidade, "sentem-se felizes em produzir, em divulgar seus trabalhos (momento de autoria)".

É preciso entender que o portfólio constitui um procedimento avaliativo completamente diferente daquele vivenciado até o momento pelos professores-alunos e também pelos mediadores. Os princípios nos quais se apóia não costumam fazer parte do trabalho pedagógico das escolas e dos cursos de formação dos profissionais da educação. A avaliação e todo o trabalho pedagógico no qual ela se insere têm sido prescritos pelos professores e pelas autoridades educacionais. De modo geral, o trabalho pedagógico visa à aquisição da aprendizagem do aluno, mas não se prevê, ao mesmo tempo, o desenvolvimento do professor e da escola. A organização do trabalho pedagógico baseado na concepção de que professores e 
alunos executem o que outros pensaram continua fortemente presente nas escolas de todos os níveis. Portanto, a proposta de utilização do portfólio é inovadora porque procura eliminar o autoritarismo ainda presente na avaliação e na organização do trabalho pedagógico. Porém, mudança provoca medo, insegurança, angústia, resistência e até mesmo sofrimento, como foi apontado.

A resistência ao uso do portfólio não é um ato isolado. Deve ser compreendida levando-se em conta a formação dos professores e o ritual pedagógico geralmente presente nas escolas onde atuam. No caso do PIE, em que os cursistas são professores em exercício, essa dualidade está presente. Só que eles têm uma formação para o magistério (em nível médio) com grandes chances de ter sido desenvolvida nos moldes tradicionais; parecem desenvolver o trabalho pedagógico dessa mesma forma, nas escolas onde trabalham, e estão vivenciando no PIE uma formação que procura superar essas dificuldades já acumuladas.

O segundo item trata do portfólio "como o mais enriquecedor procedimento de avaliação", segundo um dos mediadores. Um deles afirma:

O porta-fólio é um instrumento riquíssimo que garante a beleza da construção própria, individual, personalizada. Costumo dizer aos cursistas que é um momento de duplo prazer no processo educacional: você como autor/produtor de sua vivência e ao mesmo tempo leitor de sua obra, de sua prática, de sua atuação pedagógica. Autor e leitor de si mesmo!

Outro mediador comenta que a reação dos professores-alunos tem sido "de muita curiosidade e insegurança por ser sua primeira experiência neste tipo de avaliação".

Quanto ao terceiro item: “a gente faz o portfólio pensando em quem vai avaliar”, segundo a percepção dos mediadores, a falta de tempo para a construção do portfólio tem sido a maior dificuldade encontrada pelos professores-alunos, seguida da resistência para escrever porque "os professores de modo geral não gostam de escrever". Assim, "as primeiras reflexões são muito superficiais, com a continuação é que vão superando essa barreira”.

O quarto item revela as contribuições do portfólio para a formação dos professores-alunos. Os mediadores entendiam que a construção do portfólio, naquele momento, trazia as seguintes contribuições para a formação dos professores-alunos: visão ampliada de avaliação; 
O portfólio no curso de pedagogia: ampliando o diálogo...

vivência de avaliação processual e diferente da que eles conheciam e praticavam em suas salas de aula; registro do amadurecimento pedagógico; mudança do olhar sobre a avaliação; a prática da auto-avaliação; a busca de perspectiva de avaliação menos punitiva; construção da autonomia intelectual e profissional. O depoimento abaixo indica duas contribuiçốes:

A contribuição da reflexão e da auto-avaliação. Essa é uma das raras oportunidades que o professor-aluno tem de acompanhar, ter o registro do seu crescimento, de perceber sua mudança de conceitos, paradigmas. Acredito que sem o porta-fólio tal fato passaria quase despercebido. (Destaque meu)

O quinto item aponta "uma dificuldade imensa de não comparar as pessoas e suas produçóes”.

Ao serem indagados sobre como se sentiam ao avaliarem o trabalho de cada professor-aluno por meio do portfólio, os mediadores declararam, em sua maioria, sentir-se sobrecarregados e cansados com tantos trabalhos para analisar. Uma de suas preocupações era a de "não estar avaliando corretamente", de "não estar sendo justa". O depoimento de um dos mediadores quanto ao que sentia ao avaliar o trabalho do professoraluno por meio do portfólio parece resumir o sentimento geral:

Às vezes, co-partícipe da construção que o professor-cursista realizou; outras vezes, emocionada com a beleza das reflexões registradas, com as produções das crianças e a importância do processo desencadeado com o curso PIE na rede pública. E com uma dificuldade imensa de não comparar as pessoas e suas produções. (Destaque meu)

O sexto item fala em "guerra de concepçôes" entre os mediadores. A avaliação por meio do portfólio era nova para eles. O grupo precisou fundamentar-se teoricamente quanto à avaliação formativa. Teve também de construir seu entendimento de avaliação por meio do portfólio. Era tudo muito novo e o tempo era curto para tantas formulações. Isso gerou inquietação. Um dos depoimentos é revelador de como os mediadores se sentiam ao adotar esse procedimento: "A minha maior dificuldade é quando tratamos desse assunto, todos do PIE, pois parece que ninguém entende de portfólio e fica aquela guerra de concepções". No começo "quase enlouqueci", declarou um dos mediadores. 
O sétimo e último item apresenta necessidades e sugestôes para aprimoramento do trabalho. Dentre elas destacam-se: aprofundamento das discussōes sobre o portfólio nas coordenaçōes e tutorias; mais leituras e discussões sobre avaliação, portfólio, papel do professor e da escola, como um todo; "investir na autonomia com vistas à transformação", com o fim de "tornar o aluno sujeito do processo de avaliar".

As duas últimas necessidades demonstram que não se muda por “decreto" um processo avaliativo já arraigado, isto é, por decisão de alguém. São de fundamental importância: a fundamentação teórica que embase a formulação da concepção de avaliação formativa, a definição dos objetivos a alcançar, a seleção dos procedimentos adequados e a discussão por parte do grupo, de modo que haja unidade (não uniformidade) de ação e se adote a postura de avaliador desejada.

Os sujeitos da segunda parte da pesquisa foram 145 dos 1.000 professores-alunos que compunham o primeiro grupo de entrada no curso, com o objetivo de analisar: como se sentiam ao ser avaliados por meio do portfólio; as possibilidades e as limitações do trabalho com o portfólio; as contribuiçôes do uso do portfólio para o desenvolvimento do curso como um todo e para a avaliação praticada nas escolas onde atuavam; e os aspectos do trabalho com o portfólio a serem melhorados.

Os dados coletados foram agrupados em 11 itens de análise: a) os professores-alunos se sentiam "bem" construindo o portfólio; b) os professores-alunos resistiram no início, mas já aceitavam o trabalho com o portfólio; c) os professores-alunos se sentiam "incomodados" ou não consideravam útil o portfólio; d) portfólio $\mathrm{X}$ prova; e) portfólio e auto-avaliação; f) repercussão no trabalho pedagógico com os alunos das escolas onde atuam os professores-alunos; g) portfólio e criatividade; h) aspectos facilitadores da construção do portfólio; i) aspectos dificultadores da construção do portfólio; j) é o momento de se reverem entendimentos; k) esse processo é bom, mas... Como os dados são numerosos, apresento apenas os que se referem aos itens a, b, c, d, h, i, j e k [as informações completas estarão em Villas Boas (2004, no prelo)].

Os três primeiros itens são apresentados conjuntamente, por meio dos seguintes depoimentos de professores-alunos:

Sinto-me respeitada, porque no portfólio estou demonstrando meus avanços de forma processual, autonomia e sem me sentir pressionada por provas psicométricas. 
O portfólio no curso de pedagogia: ampliando o diálogo...

Sinto-me bem, pois percebo-me mais importante no processo avaliativo.

Gostei muito, principalmente pela autonomia.

Demorei um semestre para dar o valor correto, já que a prova estava arraigada na avaliação. Hoje reconheço que aprendo mais, cresci como profissional que participa efetivamente desse processo.

Inicialmente me sentia muito insegura e à mercê da avaliação de um mediador. Hoje já estou mais tranqüila, pois até aqui sei que não foram injustos comigo.

A princípio, houve resistência, mas com o melhor aprofundamento sobre o portfólio, as barreiras foram sendo vencidas de modo que a avaliação passou a ter um sentido mais amplo, proporcionando um acompanhamento do meu crescimento pessoal e profissional.

No início do curso, me sentia péssima. Fazer uma prova seria mais fácil...

Esse processo de avaliação ainda não me deixa totalmente à vontade. Percebo que estou crescendo pedagogicamente, mas isso não se deve ao portfólio e, sim, consciência e crítica pessoal.

No início do curso, resisti bastante, fiquei insegura, mas, atualmente, me sinto mais tranqüila e com mais autonomia para decidir o que quero e o como quero.

Às vezes me sinto como se alguém observasse meu interior, outras vezes, inibida em expor o que faço, por saber que outros estarão analisando o meu trabalho.

Espionado, porque as produções e reflexões são muito pessoais para alguém dizer se está certo ou errado.

Acredito que ele deve ser mais um instrumento e não "o instrumento". Deve ser avaliado em conjunto com outros para uma avaliação mais completa e eficiente.

O porta-fólio como único meio de avaliação prejudica o aluno.

Acho que as discussões em sala de aula devem ser tão valorizadas quanto o portfólio.

Os depoimentos que revelam incômodo com o uso do portfólio parecem indicar que o processo de avaliação do PIE ainda não está compreendido por todos. A reivindicação de que o portfólio não seja "o único instrumento" de avaliação é bem colocada e precisa ser analisada pelos coordenadores do curso. Os professores-alunos estão percebendo que o processo não está completo. Como serão consideradas as evidências 
de aprendizagem que não podem ser inseridas no portfólio, como a participação em seminários e as discussões em sala de aula, segundo eles próprios apontam, e outras? Têm razão os professores-alunos de desejar que ele se associe a outros procedimentos. Isso demonstra que estão se apropriando da intenção e do mérito do portfólio.

O fato de o professor-aluno se sentir "espionado" e considerar suas produções tão íntimas que outra pessoa não deve avaliá-las pode indicar o quanto ele percebe que o portfólio lhe pertence. Em contrapartida, ele foi adotado para substituir a avaliação tradicional. Não se pode desvirtuar as intenções da utilização do portfólio no curso. Ele de fato é de propriedade do aluno, não cabendo ao mediador ficar com ele ao final do curso. Porém, o seu caráter é o de demonstrar o progresso do aluno. Deve ser considerado uma produção acadêmica cujo formato é decidido pelo aluno, para que ele e o professor, no caso o mediador, analisem o seu progresso.

Outro aspecto é apontado nos depoimentos: a "angústia" que alguns professores-alunos estão vivendo. A avaliação desenvolvida quase exclusivamente por meio de provas já era tão conhecida que, substituí-la por um procedimento mais amplo, parece estar causando insegurança. É bom lembrar que um dos princípios que norteiam o uso do portfólio é a parceria entre professor-aluno e aluno-aluno. $\mathrm{O}$ trabalho não deve ser solitário nem angustiante. $\mathrm{O}$ que se pretende é justamente praticar avaliação mais justa, isto é, que leve em conta todo tipo de produção do aluno, por meio de diferentes linguagens. Por parceria na avaliação entende-se que o professor deixe de ser o único avaliador e o aluno, o único avaliado. Isso requer mudança de postura avaliativa. Contudo, é preciso que fique bem claro: nova postura em avaliação não significa entender que agora tudo é aceito, de qualquer jeito; muito pelo contrário, é uma avaliação conduzida com mais rigor e seriedade. A apresentação de evidências de aprendizagem, por meio de diferentes linguagens, torna o processo mais rico e transparente e o aluno mais exigente quanto ao seu papel e ao do professor.

O item portfólio X prova contrapõe esta ao portfólio, como se pode perceber: Creio ser o melhor método (instrumento) de avaliação do que a prova, pois, ao construir o portfólio, é necessário que eu pesquise, reflita e busque entender o que estou fazendo. Além disso, percebo o quanto estou crescendo intelectualmente. 
O portfólio no curso de pedagogia: ampliando o diálogo...

Sinto-me melhor compreendida, pois posso mostrar mais o quanto me dedico a buscar coisas novas, ao contrário das avaliaçóes por provas.

O portfólio é uma construção muito rica, embora muito mais trabalhosa do que estudar para uma prova e realizá-la. Isso causa angústia em alguns colegas.

Cabe salientar que o portfólio não é um substituto para a prova, porque é muito mais abrangente que ela. Esta nem deve ser abolida. No contexto da avaliação formativa, ela não pode ser o único procedimento adotado. Dependendo da situação, se ela for utilizada, será uma das evidências de aprendizagem a serem incluídas no portfólio ou poderá ser outro procedimento a compor o processo de avaliação.

$\mathrm{O}$ item que trata dos aspectos facilitadores inclui como os mais freqüentes: os trabalhos em grupo; a socialização do portfólio; a autonomia; integração teoria e prática; desenvolvimento da criatividade; uso de diferentes linguagens.

Como aspectos dificultadores, nono item de análise, foram apontados pela maioria dos professores-alunos: o tempo escasso de que dispunham para a construção do portfólio e a falta de computador pessoal.

No item "É hora de se reverem entendimentos", os depoimentos explicam os motivos de os professores-alunos não usarem o portfólio com seus alunos:

Falta de tempo, de recursos, insegurança; tendo dificuldade para a construção do meu porta-fólio, como trabalhar com o aluno?

Falta de iniciativa e até de planejamento.

Parece ser um contra-senso. Sou muito a favor da adoção do portfólio, mas não tenho me dedicado a desenvolver este trabalho em minha atividade docente. Quando chego à escola, parece que estou vivendo em um outro mundo e o sistema tem me desanimado muito. (Destaque meu)

O último depoimento parece traduzir a solidão pedagógica vivida pelos professores em seu trabalho.

Os professores-alunos que afirmam já adotar o portfólio com seus alunos ainda o fazem com insegurança, limitações e, principalmente, sem apoio da direção da escola. Um trabalho como esse deve ser organizado pela escola como um todo. O grupo de professores precisa ter toda a orientação necessária e os pais devem ser preparados para acompanhar, compreender e aceitar o processo. 
O último item de análise apresenta as justificativas dos que ainda não se dispõem a "arregaçar as mangas" para enfrentar os desafios da avaliação. Assim eles se manifestaram: "Esse processo é bom, mas...

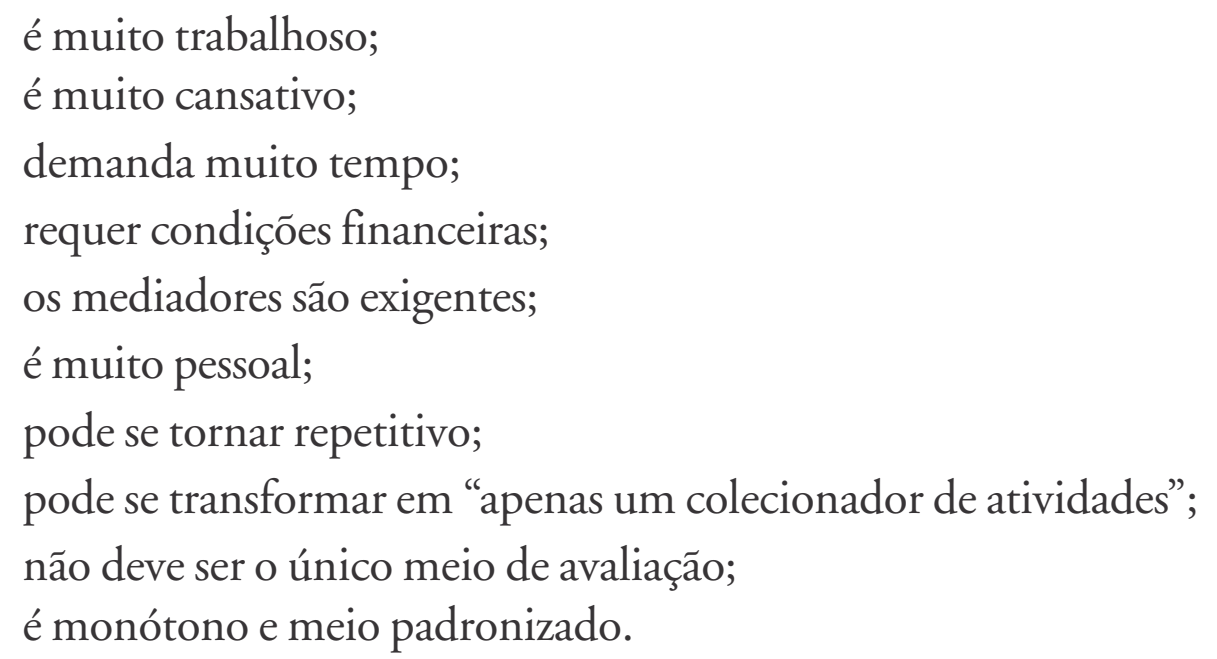

As respostas dos professores-alunos ao questionário revelaram estas percepções anteriores, com relação às ressalvas que fazem ao uso do portfólio. Esses "mas" é que precisam ser analisados por todos os que se envolvem em sua construção. Passado o primeiro momento de contato dos mediadores e dos professores-alunos com esse procedimento de avaliação, quando foi dada a largada para a adoção de um procedimento que rompa com a avaliação tradicional, surgiu o segundo momento, de reflexão sobre o que já foi obtido e sobre as necessidades de avanço. Não se pode esquecer de que está sendo avaliada a aprendizagem de professores em exercício, os quais, enquanto têm o seu trabalho no curso avaliado, também avaliam seus alunos. Esse fato traz uma responsabilidade muito grande para o curso. Neste aspecto ele tem sido singular: não se tem notícia de um Curso de Pedagogia para professores em exercício no início da escolarização que atenda a um número tão grande de cursistas e utilize esse procedimento de avaliação. As informaçōes fornecidas pelos professores-alunos indicam a possibilidade de ampliação do processo de tomada de decisóes do qual eles participam. É o momento de avançar, dando-lhes a chance de selecionarem as atividades que demonstrem a sua aprendizagem. Contudo, cabe agir com prudência. A dimensão dessa ampliação de tomada de decisão pode ser discutida por cada mediador com os grupos com os quais trabalha. Não há necessidade de padronização das ações no curso como um todo. Os mediadores também estão em condições de identificar até que ponto a sua tur- 
O portfólio no curso de pedagogia: ampliando o diálogo...

ma pode avançar, sem prejuízos. A participação nesse processo é fundamental. Ela também será uma aprendizagem importante para todos os envolvidos. Como nos ensinam Freire \& Shor (1986, p. 114), é impossível "ensinar participação sem participação! É impossível só falar em participação sem experimentá-la”.

\section{Confrontando os dados da pesquisa}

As informações fornecidas pelos mediadores e pelos professoresalunos permitem a formulação das reflexões que se seguem.

- Mudar a cultura avaliativa é um processo longo, lento e coletivo. No PIE a adoção do portfólio tem dado resultados satisfatórios porque: a) o currículo é constituído por temas integradores e não por disciplinas isoladas e oferecidas por professores que, individualmente, decidem a condução do trabalho pedagógico; b) os mediadores coordenam o trabalho pedagógico como um todo e o portfólio é o procedimento de avaliação utilizado por todos; c) o planejamento do trabalho pedagógico é feito coletivamente, sistematicamente, por meio de encontros semanais de todo o grupo; d) os mediadores participam da tomada de decisões e da construção dos documentos orientadores. As decisóes sobre o processo avaliativo são tomadas com a participação de todos os mediadores, que são os docentes do curso. Trata-se de um processo realmente colaborativo, desenvolvido com unidade de pensamento e ação. Como conseqüência, os mediadores são os próprios construtores do processo de trabalho, o que constitui aprendizagem para eles e para os professores-alunos.

- O portfólio ainda é percebido por alguns professores-alunos como um "instrumento". Há a solicitação de que ele não seja o único procedimento de avaliação. Um dos mediadores apresentou como uma das dificuldades:

A avaliação subjetiva do mediador. Eles (professores-alunos) reclamam que dão o máximo de si, mas este máximo está representando o mínimo para o mediador. Percebo que existe uma lacuna nessa avaliação, mas não sei qual é. (Destaque meu) 
A lacuna a que o(a) mediador(a) se refere pode ser o seu entendimento de que o portfólio não é suficiente para avaliar todas as dimensōes da aprendizagem. Como a substituição da avaliação tradicional por um processo que valorize a aprendizagem de todos os alunos, levando em conta as diferentes linguagens, está em construção pelo grupo, o passo seguinte é a definição de outros procedimentos que, juntamente com o portfólio, compóem o processo avaliativo do curso. Vários depoimentos apontam essa percepção pelos professores-alunos. Um forte argumento para isso é o seguinte: o portfólio é construído pelo professor-aluno. Assim sendo, como considerar os dados da avaliação feita pelo mediador, pela observação e pelas conversas informais com os professores-alunos? Como considerar a avaliação informal? Inevitavelmente ela está presente. Como tirar proveito dela? A resistência de alguns professores-alunos em ter o seu portfólio avaliado por outra pessoa e até mesmo o fato de um deles se sentir "espionado" parece apoiar-se na crença de que ele não pode ser o único procedimento de avaliação.

- Os depoimentos dos mediadores e dos professores-alunos revelam que a avaliação por meio do portfólio está direcionando a organização e o desenvolvimento do trabalho pedagógico do PIE. Vale a pena salientar trechos de alguns dos depoimentos de professores-alunos: "entro em contato com minhas produçôes"; "utilizo minha criatividade"; "uso minha autonomia"; "chances de crescer"; "construir coisas belas e que têm mais sentido para mim"; "sinto-me diferente"; "crio minha avaliação"; "meu trabalho é valorizado"; "acompanho meu desenvolvimento" etc. Tudo isso faz crer que o portfólio está mudando o rumo da formação desses professores-alunos. A antiga prática de "transmissão de conhecimentos", de trabalho isolado e solitário por parte dos alunos e de avaliação unilateral, seletiva e excludente está cedendo lugar ao processo de trabalho em que predominam a construção, a reflexão, a criatividade, a parceria, a auto-avaliação e a autonomia.

Recebido em junho de 2004 e aprovado em fevereiro de 2005.

Referências bibliográficas

CONTRERAS, J. A autonomia de professores. São Paulo: Cortez, 2002. 
O portfólio no curso de pedagogia: ampliando o diálogo...

FREIRE, P.; SHOR, I. Medo e ousadia: o cotidiano do professor. Rio de Janeiro: Paz \& Terra, 1986.

MURPHY, S. Teachers and students: reclaiming assessment via portfolios. In: YANCEY, K.B.; WeISER, I. (Ed.). Situating portfolios: four perspectives. Logan, Utah: Utah State University Press, 1997. p. 72-88.

TARDIF, M. Saberes docentes e formação profissional. Petrópolis: Vozes, 2002.

VILLAS BOAS, B.M.F. Avaliação formativa: em busca do desenvolvimento do aluno, do professor e da escola. In: VeIGA, I.P.A.; FonseCA, M. (Org.). As dimensóes do projeto político-pedagógico: novos desafios para a escola. Campinas: Papirus, 2001. p. 175-212.

VILLAS BOAS, B.M.F. Portfólio, avaliação e trabalho pedagógico, 2004 (no prelo). 